Revista Universo Contábil, ISSN 1809-3337

Blumenau, v. 14, n. 2, p. 61-81, abr./jun., 2018

doi:10.4270/ruc.2018211

Disponível em www.furb.br/universocontabil

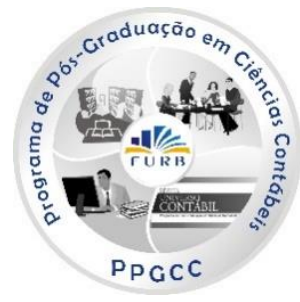

\title{
ESTRATÉGIAS DAS COORDENAÇÕES DOS CURSOS DE CIÊNCIAS CONTÁBEIS PARA COMBATER A EVASÃO ${ }^{1}$
}

\section{STRATEGIES OF ACCOUNTING SCIENCES COURSE COORDINATION TO COMBAT EVASION \\ ESTRATEGIAS PARA CONTRARRESTAR LA DESERCIÓN ESCOLAR EN LA CARRERA DE CONTABILIDAD}

\author{
Izaqueline Jhusmicele Alcântara da Silva \\ Graduanda do curso de Ciências Contábeis pela Universidade Federal de Uberlândia \\ Endereço: Av. João Naves de Ávila, 2.121, Bloco F - Campus Santa Mônica \\ CEP: 38400-902 - Uberlândia - MG - Brasil \\ E-mail: izaqueline@hotmail.com \\ Telefone: (34) 99208-2782
}

Gilberto José Miranda Doutor em Contabilidade e Controladoria pela Universidade de São Paulo Professor Adjunto da Universidade Federal de Uberlândia Endereço: Av. João Naves de Ávila, 2.121, Bloco F - Campus Santa Mônica CEP: 38400-902 - Uberlândia - MG - Brasil E-mail: gilbertojm@ufu.br Telefone: (34) 3239-4176

Edvalda Araújo Leal Doutora em Administração pela Fundação Getúlio Vargas Professora Adjunta da Universidade Federal de Uberlândia Endereço: Av. João Naves de Ávila, 2.121, Bloco F - Campus Santa Mônica CEP: 38400-902 - Uberlândia - MG - Brasil E-mail: edvalda@ufu.br Telefone: (34) 3291-5904

Janser Moura Pereira Doutor em Estatística e Experimentação Agropecuária pela Universidade Federal de Lavras Professor Adjunto da Universidade Federal de Uberlândia

Faculdade de Matemática E-mail: jansermp@gmail.com

Telefone: (34) 3239-4234

\footnotetext{
${ }^{1}$ Artigo recebido em 22/07/2017. Revisado por pares em 05/10/2018. Reformulado em 06/12/2018. Recomendado para publicação em 29/01/2019 por Marcia Zanievicz Silva. Publicado em 20/02/2019. Organização responsável pelo periódico: FURB.
} 


\section{RESUMO}

A evasão escolar é um fenômeno presente no sistema educacional público e privado que gera grandes impactos sociais. No ensino superior brasileiro, as taxas de evasão, nos cursos presenciais e a distância, correspondem a $24,9 \%$ e $28,8 \%$, respectivamente. O presente estudo se propôs a analisar e identificar, na percepção dos coordenadores de curso, as ações de retenção praticadas nos cursos de Ciências Contábeis do Brasil e a sua relação com o nível de evasão da IES. A amostra ficou composta por 155 coordenadores vinculados a IES privadas $(83,2 \%)$ e públicas $(16,8 \%)$ de todas as regiões brasileiras. Para tratamento dos dados, foram utilizadas a estatística descritiva, as comparações múltiplas de proporções, as comparações de médias e a regressão linear múltipla. Os resultados da regressão demonstraram que as IES em que a coordenação promove a integração acadêmica dos alunos tendem a apresentar menores taxas de evasão, incluindo-se ações para acompanhamento e intervenção em relação às dificuldades de ensino-aprendizagem ao longo do curso. Também se mostraram relevantes o acompanhamento à frequência do aluno, bem como o oferecimento de orientações sobre o curso aos alunos no ato de matrícula. Identificou-se ainda que os cursos do turno noturno apresentam maiores índices de evasão se comparados aos do turno integral. Os testes estatísticos, por sua vez, indicaram que as bolsas de auxílio financeiro e os descontos nas mensalidades escolares oferecidas pelas IES, bem como a oferta de monitorias ou atendimento extraclasse para suprir deficiências do aluno ao longo do curso, tendem a reduzir as taxas de evasão. Infere-se, com base nos resultados, que, à medida que IES, coordenadores e docentes adotarem estratégias semelhantes a essas, e que contribuam com o debate sobre políticas que visem à retenção dos estudantes universitários, o fenômeno da evasão poderá ser erradicado ou, pelo menos, minimizado no meio universitário.

Palavras-chave: Evasão, Coordenação de curso, Ensino Superior, Ciências Contábeis, Estratégias.

\section{ABSTRACT}

School evasion is a phenomenon present in the public and private educational system that generates great social impacts. In Brazilian higher education, evasion rates, in face-to-face courses and at distance correspond to $24.9 \%$ and $28.8 \%$, respectively. The present study aimed to analyze and identify, in the perception of the course coordinators, the retention actions practiced in the courses of Accounting Sciences in Brazil and its relation with the level of evasion of the HEI. The sample consisted of 155 coordinators linked to private $(83.2 \%)$ and public HEIs (16.8\%) from all Brazilian regions. For data treatment the descriptive statistics, multiple comparisons of proportions, average comparisons and multiple linear regression were used. The regression results showed that HEIs in which the coordination promotes students' academic integration tend to have lower evasion rates, including actions for follow-up and intervention in relation to teaching-learning difficulties throughout the course. Also relevant were the monitoring of the student's attendance and the provision of orientation to the students on the course in the enrollment time. It was also identified that the courses in the night shift present higher evasion indices when compared to the whole shift. Statistical tests also indicated that financial aid scholarships and discounts in school fees offered by HEI, as well as the provision of extra-class attendance or attendance to fill student's deficiencies throughout the course tend to reduce evasion rates. It is expected that as higher education institutions adopt strategies aimed at school retention, student evasion rates can be minimized.

Keywords: Evasion, Course coordination, Higher Education, Accounting Sciences, Strategies. 


\section{RESUMEN}

Las tasas de deserción escolar en la carrera de ciencias contables para los cursos de educación presenciales y a distancia son de 24,9 y 28,8 \%, respectivamente; siendo este un fenómeno prevaleciente en la Educación Superior Brasileña, pública y privada, causante de importantes impactos sociales. El presente estudio se propone como objetivo fundamental analizar e identificar las acciones de retención escolar practicadas por los Institutos de Educación Superior, de acuerdo con la percepción de los coordinadores de carrera y su relación con las tasas de deserción prevalecientes. La muestra fue compuesta por 155 coordinadores de carrera del país, con una representación de $83,2 \%$ de instituciones privadas y $16,8 \%$ de instituciones públicas. Para el tratamiento de los datos se utilizó la estadística descriptiva, comparaciones múltiples de proporciones, comparaciones de medias y el método de regresión lineal múltiple. Los resultados de la regresión demuestran que las instituciones donde los coordinadores promueven acciones para desarrollar un proceso de enseñanza-aprendizaje diferenciado, para alumnos con dificultades académicas, obtienen menores tasas de evasión escolar. Se evidenció que los cursos nocturnos presentan mayores tasas de deserción en relación al curso integral, las pruebas estadísticas aplicadas indicaron que las bolsas de auxilio financiero, los descuentos en las mensualidades escolares ofrecidas por las instituciones académicas, las ofertas de monitorias y la atención diferenciada extraclase, son factores que tienden a disminuir los índices de deserción escolar. Se espera que en la medida que las instituciones de educación superior adopten estrategias direccionadas a la retención escolar, la tasa de evasión de alumnos podrá ser minimizada.

Palabras Claves: Tasas de deserción escolar, Coordinación carrera de contabilidad, Tasa de deserción en ciencias contables, Estrategias para la deserción escolar, Enseñanza superior.

\section{INTRODUÇÃO}

Em 2013, a evasão dos cursos presenciais atingiu o índice de 24,9\%, sendo 17,8\% nas Instituições de Ensino Superior (IES) públicas e 27,4\%, na rede privada. Nos cursos EAD, o índice chegou a $28,8 \%$, sendo $25,6 \%$ nas IES públicas e 29,2\%, na rede privada [Sindicato das Mantenedoras de Ensino Superior (SEMESP), 2015]. Isso significa que, em média, de cada quatro alunos que ingressam no ensino superior, um não consegue concluir o curso.

O Curso de Ciências Contábeis tem crescido gradativamente ao longo dos últimos anos, posicionando-se em quarto lugar entre os maiores cursos de graduação do Brasil no número de matrículas, sendo essa a mesma posição ocupada em 2009 (INEP, 2017). Entretanto, o crescimento no número de matrículas no curso é acompanhado pelo aumento nas taxas de evasão, conforme apontam Silva Filho et al. (2007). Esses autores observaram que, na área de Ciências Sociais, Negócios e Direito, na qual se inclui o curso de Ciências Contábeis, o índice médio de evasão é de 25\%, acima da média nacional, que é de 22\%, no período de 2000 a 2005.

A partir desses dados, a evasão torna-se se um tema relevante para as IES. Baggi e Lopes (2011) entendem a evasão como a saída do aluno do sistema de ensino. Tinto (1975) enxerga essa saída de duas formas: abandono voluntário e abandono involuntário. O primeiro tipo ocorre devido à inadaptação do estudante ao regime social e ao ambiente oferecido pela IES. Já o segundo é resultante do insucesso acadêmico do discente. Assim, esse processo de abandono do aluno se daria conforme o seu nível de integração à vida universitária (TINTO, 1975).

Independentemente da forma como ocorre, a saída do aluno da Instituição antes da conclusão do curso impacta a sociedade como um todo, pois representa desperdício de recursos públicos sem retorno para a sociedade, além de provocar ociosidade das vagas ofertadas, o que representa uma perda de receita de $2 \%$ a $6 \%$ para as universidades privadas (SILVA FILHO et al., 2007). De acordo com Paes Barros et al. (2016), a pesquisa encomendada pela Fundação 

A EVASÃO

Brava, Insper, Instituto Ayrton Senna e Instituto Unibanco revelou que os prejuízos individuais que os jovens brasileiros evadidos terão durante sua vida é de cerca de R $\$ 14$ bilhões. Além disso, outros $R \$ 35$ bilhões por ano são atribuídos aos custos sociais com a evasão que são pagos por toda a sociedade (gastos com saúde pública, segurança, valores que deixam de ser arrecadados com impostos, entre outras variáveis que, comprovadamente, são afetadas pela menor escolaridade do indivíduo). Juntos, esses gastos somam um montante praticamente igual ao gasto que o país tem hoje com o ensino médio, que é da ordem de $\mathrm{R} \$ 50$ bilhões anuais.

Lobo (2012) destaca a responsabilidade do governo no oferecimento de ensino de qualidade e no uso responsável dos recursos, asseverando a importância do estudo da evasão por parte dos órgãos governamentais no tratamento da problemática. Baggi e Lopes (2011) complementam que há necessidade de políticas públicas educacionais que visem atenuar a desigualdade entre os alunos, reconhecendo os autores o despreparo das IES públicas e privadas no fornecimento de suporte para a permanência do discente no seio universitário.

No Brasil, a fomentação de estudos nessa área se deu após a criação, em 1995, da Comissão Especial de Estudos sobre Evasão, por meio da Portaria da Secretaria de Educação Superior e do Ministério da Educação (SESU/MEC), que tinha como objetivo promover estudos sobre o desempenho de instituições públicas de ensino superior (BARDAGI; HUTZ, 2009). Assim, nos últimos anos, muitas pesquisas têm se dedicado à identificação das causas da evasão. Os resultados evidenciam como causas a falta de orientação vocacional, falta de suporte financeiro, descontentamento com o curso ou com a profissão, absenteísmo, reprovação, falta de integração entre ensino e mercado de trabalho, desmotivação discente, desigualdade cultural, entre outras (SILVA FILHO et al., 2007; ANDRIOLA, 2009; DIAS; THEÓPHILO; LOPES, 2010; KRUGER JÚNIOR et al., 2011; BAGGI; LOPES, 2011; CUNHA et al., 2015; DIOGO et al., 2016).

No entanto, em menor proporção, existem estudos dedicados à investigação de estratégias de sucesso para o combate à evasão, notadamente, no campo da Contabilidade. Conforme expõem Munizaga, Cifuentes e Beltrán (2018), ao investigar, por meio de uma revisão da literatura, o abandono e a retenção no ensino superior na América Latina, os autores constatam que, dos 81 artigos levantados, apenas 6\% abordavam a evasão e $11 \%$ tinham o objetivo de propor e acompanhar ações de intervenção para a diminuição das taxas de evasão.

Diante do exposto, o presente estudo se propõe a identificar: que tipos de estratégias adotadas pelas Instituições de Ensino Superior (IES), que oferecem o curso de Ciências Contábeis no Brasil, têm associação com o combate à evasão? Assim, o objetivo é identificar e analisar as estratégias adotadas pelas IES para o curso de Ciências Contábeis e identificar suas relações com os índices de evasão.

A presente pesquisa justifica sua relevância embasada na importância do estudo da evasão com o intuito de identificar ações para retenção universitária. Com base na análise de regressão múltipla, o estudo aborda as causas que levam à evasão, fatores internos e externos que incidem na evasão e os tipos predominantes desse fenômeno que ocorrem nas IES. A escolha da área contábil decorre por apresentar uma demanda crescente dos estudantes (INEP, 2017), embora com taxas médias de evasão também crescente (SILVA et al., 2007). Ao final, espera-se contribuir com o debate sobre políticas que visem à retenção dos estudantes universitários e que proporcionem redução das perdas financeiras, públicas e privadas, pessoais e sociais decorrentes da evasão (SILVA FILHO et al., 2007; LOBO, 2011; CUNHA; NASCIMENTO; DURSO, 2014; GOIS, 2016).

\section{O FENÔMENO EVASÃO}

A evasão escolar é um fenômeno presente no sistema educacional público e privado que gera impactos na sociedade como um todo. Para adequada análise da temática, torna-se necessário caracterizá-la, revisar os conceitos, identificar os tipos de evasão, como ela é 
mensurada, época de maior incidência no curso, além das principais causas e estratégias para combatê-la.

Segundo Krüger Júnior et al. (2011, p. 3), evasão significa "fuga, desistência, abandono" do curso. Já a comissão Especial do Ministério da Educação (MEC) define-a como "a saída definitiva do aluno de seu curso de origem, sem concluí-lo" (BRASIL, 1996, p. 15). Entretanto, Bueno (1993, p. 5) destaca a diferença entre as formas de "saída" do discente da instituição, distinguindo "evasão" de "exclusão". Segundo o autor, a evasão ocorre quando o "aluno decide desligar-se por sua própria responsabilidade", enquanto a exclusão "implica na admissão de uma responsabilidade da escola e de tudo que a cerca por não ter mecanismo de aproveitamento e direcionamento do adolescente que se apresenta para uma formação profissionalizante". Neste estudo, assume-se que as duas ocorrências serão denominadas por evasão.

Para o MEC (BRASIL, 1996, p. 16), existem três tipos de evasão: (i) evasão do curso, que ocorre quando o estudante se desliga do curso superior em situações diversas, tais como, abandono (deixa de matricular-se), desistência (oficial), transferência ou reopção (mudança de curso), exclusão por norma institucional; (ii) evasão da instituição, que ocorre quando o estudante se desliga da instituição na qual está matriculado; e (iii) evasão do sistema, que é a que se dá quando o estudante abandona de forma definitiva ou temporária o ensino superior.

No tocante à mensuração, Silva Filho et al. (2007) informam que o cálculo da evasão é medido de duas formas: evasão total e evasão média semestral/anual. A primeira é utilizada para se verificar a quantidade de alunos que, tendo ingressado em um sistema de ensino, não obtiveram o diploma ao final do período estabelecido. Já a evasão média é utilizada para medir a porcentagem de alunos que, matriculados na instituição, e não tendo se formado, não se matricularam no semestre ou no ano seguinte (SILVA FILHO et al., 2007). Estudos que mensuram a evasão mostram também que a maior parte dos alunos desiste no primeiro ano do curso, sendo esse um índice duas a três vezes maior do que aquele percebido nos anos subsequentes (BUENO, 1993; SILVA FILHO et al., 2007; DIAS; THEÓPHILO; LOPES, 2010).

Tinto (1975), com base na teoria do suicídio de Durkheim, comparou o ato de desistência no ensino superior como uma forma de suicídio, ou seja, o suicídio acadêmico. Sobre esse aspecto, o autor propõe o Modelo de Integração do Estudante (MIE), relacionando o contexto social no qual o aluno está inserido com a Instituição de Ensino Superior em que ele está matriculado, indicando variáveis que afetam o processo de evasão. Com esse modelo longitudinal, o ato de persistir ou de desistir da graduação é analisado em dois momentos: o período pré-universitário e o período universitário. O primeiro está ligado às características do estudante, às suas intenções/objetivos e compromissos e às expectativas com a carreira. $\mathrm{O}$ segundo refere-se às características do curso, ao nível de integração acadêmico e social, às suas intenções/objetivos e compromissos e a fatores externos, visto que a integração acadêmica está ligada ao desempenho do aluno e seu compromisso com as normas institucionais. Já integração social refere-se às relações estabelecidas com os professores, colegas de classe e à presença nas atividades extracurriculares oferecidas pela IES (TINTO, 1975).

Posteriormente, ao revisar seu modelo, Tinto (1993) acrescentou novas variáveis: aprendizagem, finanças, ajustamento, incongruências, dificuldades e compromissos externos. A Figura 1 ilustra o modelo longitudinal do abandono institucional proposto por Tinto (1993). Segundo o autor, é essencial manter um equilíbrio entre o aspecto acadêmico e o social, de modo que a falta de integração acadêmica ou o excesso de integração social podem resultar em notas baixas e descumprimentos das regras, o que causará insatisfação e desmotivação do aluno ou um abandono forçado (TINTO, 1975). 

A EVASÃO

Figura 1: Modelo longitudinal do abandono institucional (Tinto, 1993)

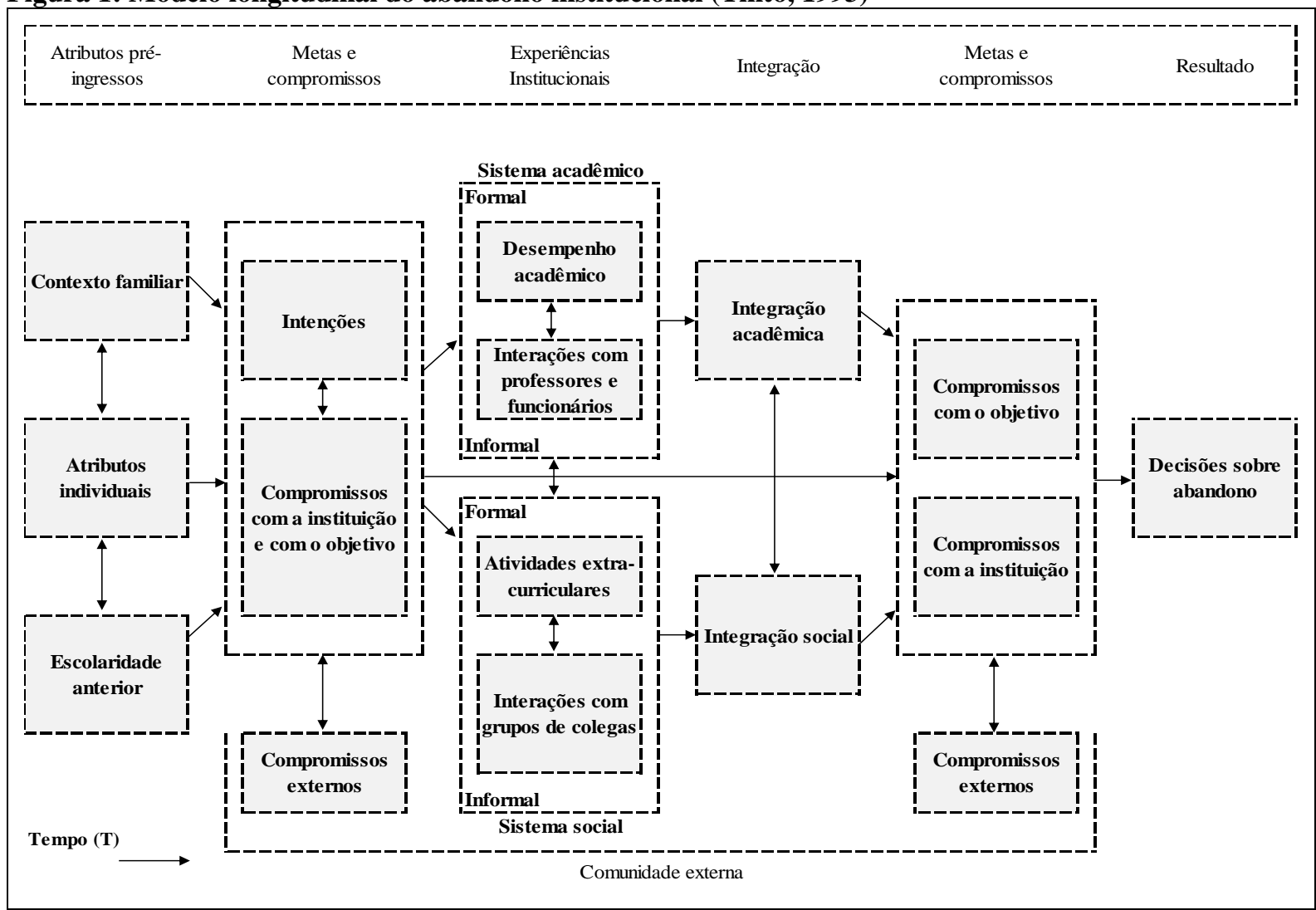

Fonte: Tinto (1993).

As variáveis ligadas à evasão são resultantes de causas internas e externas. Para combater esse fenômeno, as estratégias, no período pré-universitário, são direcionadas às causas externas à universidade, enquanto, no período universitário, as estratégias são direcionadas às causas internas (TINTO, 1975/93; DIAS; THEÓPHILO; LOPES, 2010). Em relação às causas internas, os autores apontam: infraestrutura; corpo docente; e assistência socioeducacional. As causas externas são: falha na tomada de decisão em relação ao curso; dificuldades escolares; razões socioeconômicas; distância entre domicílio e universidade; e problemas pessoais (TINTO, 1975/93; BUENO, 1993; SILVA FILHO et al., 2007; DIAS; THEÓPHILO; LOPES, 2010; CUNHA, NASCIMENTO; DURSO, 2015).

Considerando-se que foram realizadas diversas pesquisas que investigaram a evasão no ensino superior, envolvendo as variáveis pertencentes ao modelo proposto por Tinto (1993), torna-se relevante apresentar os principais resultados evidenciados nesses estudos.

Quanto ao corpo docente, Silva (2013) aborda que, no decorrer da graduação, é comum a presença de professores com baixa qualificação pedagógica, principalmente, nas disciplinas introdutórias dos cursos. Segundo o autor, tal fato implica em fragilidades na apresentação da relação teoria e prática na atuação profissional, desmotivando os estudantes e influenciando no aumento da evasão. Além disso, Bueno (1993, p.12) expõe que a formação escolar básica brasileira é precária, dando-se em forma de "orientação rígida e meramente reprodutora de conhecimento [...]", e, ainda, não prepara o aluno para o ensino superior, que é quando será exigido dele exercícios de caráter crítico.

Diogo et al. (2016) entendem que os alunos ingressam no ensino superior sem a consciência das diferenças em relação ao ensino médio e, ao se depararem com disciplinas complexas, sentem sensação de inaptidão. Ao questionar os coordenadores dos 10 cursos de graduação com os índices brutos mais elevados de reprovação, evasão e frequência insuficiente de uma universidade federal localizada no sul do país, os autores puderam relacionar o 
despreparo e a deficiência da formação básica do aluno ingressante ao fenômeno da evasão, além de apontar a falta de articulação da teoria com a prática e as reprovações nas fases iniciais (DIOGO et al., 2016).

Quanto aos atributos pré-ingresso indicados por Tinto (1993), a questão vocacional tem forte influência no abandono do ensino superior. A decisão pela escolha profissional no Brasil é realizada precocemente, ou seja, antes mesmo do ingresso na graduação, muitos jovens já estão atuando no mercado de trabalho, diferentemente do que ocorre em outros países (BARDAGI; HUTZ, 2009). Além disso, os estudantes, na fase do ensino médio, não recebem o apoio necessário para a compreensão da vocação profissional, sendo suas escolhas influenciadas por imposição familiar (BARDAGI, 2007; DIAS, THEÓPHILO; LOPES, 2010; CUNHA; NASCIMENTO; DURSO, 2016). Nesse sentido, a pesquisa de Cunha, Nascimento e Durso (2016) identificou que 91\% dos 348 estudantes do curso de Ciências Contábeis de universidades públicas da região sudeste alegaram não ter tido a ajuda de um especialista em orientação vocacional. Esse resultado é corroborado pelos dados do Censo Nacional da Educação Superior. Além da escolha profissional, outros estudos apresentam os fatores determinantes para o sucesso ou insucesso do discente, quais sejam: as expectativas do estudante quanto ao curso; a adaptação à vida universitária, à instituição e à comunidade; e a sua condição financeira (BUENO, 1993; SILVA FILHO et al., 2007; DIAS; THEÓPHILO; LOPES, 2010).

No que tange aos fatores socioeconômicos, Silva Filho et al. (2007) asseveram que a falta de recursos financeiros é tratada como a principal causa de desistência do curso superior. Conforme mencionado anteriormente, a pesquisa realizada por Silva (2013) analisou os principais determinantes da evasão em instituições de ensino privadas e, dentre os achados, o autor evidenciou que o aumento nas mensalidades e a ausência de pagamentos estão fortemente relacionados com a probabilidade de abandono do curso de graduação. Dias, Theóphilo e Lopes (2010) desenvolveram um estudo com os alunos do curso de Ciências Contábeis sobre o tema evasão e constataram que um percentual representativo de alunos alegou ter cometido um erro quanto à escolha do curso. Os autores evidenciaram também que os alunos apresentam dificuldades no processo de adaptação à realidade acadêmica, indicando como limitadores a moradia em outra cidade, a distância entre a residência e a universidade, casamento, questões de saúde, necessidade de sustentar a família, troca de emprego e também dificuldades no ensino. Foram mencionadas ainda dificuldades de adaptação às práticas/métodos adotados pelos professores e a pouca identidade entre o perfil do egresso e o do aluno (DIAS; THEÓPHILO; LOPES, 2010).

Em uma pesquisa sobre a percepção dos coordenadores de curso de uma instituição pública, Andriola (2009) identificou, por meio de entrevistas, que eles consideram ser papel da coordenação disponibilizar informações sobre o curso e a carreira. Nesse sentido, os coordenadores sugeriram a realização de seminários e disciplinas introdutórias, visitas às escolas do ensino médio e a divulgação de informações sobre os cursos por meio da internet.

Com base nos estudos acima, segue uma sintetização das principais estratégias mencionadas pelos autores, como ilustrado no Quadro 1:

Diante do exposto, fica evidente a necessidade de políticas sociais e institucionais voltadas a identificar e sanar as dificuldades encontradas pelos alunos no seu percurso universitário. Por isso, fica clara a relevância dos estudos que se dedicam ao fenômeno da evasão, visto que muitos gastos financeiros são desperdiçados quando um estudante abandona a vaga na IES, e mesmo para a sociedade, que perde a oportunidade de poder contar com mais um profissional qualificado (SILVA FILHO et al., 2007; CUNHA; NASCIMENTO; DURSO, 2016). 

A EVASÃO

Quadro 1: Síntese das Estratégias adotadas para minimizar a evasão

\begin{tabular}{|c|c|}
\hline Estratégias & Fontes \\
\hline - Suporte financeiro. & \multirow{6}{*}{ Diogo et al. (2016) } \\
\hline - Curso de nivelamento/Apoio pedagógico. & \\
\hline - Oferta de eventos informativos. & \\
\hline $\begin{array}{l}\text { - Oferta de atividades extracurriculares, tais como: visitas técnicas, empresa } \\
\text { júnior, eventos de ensino, pesquisa e extensão. }\end{array}$ & \\
\hline $\begin{array}{l}\text { - Garantir espaços de discussão sobre carreira, mercado de trabalho e opções } \\
\text { de profissionalização. }\end{array}$ & \\
\hline $\begin{array}{l}\text { - Incentivo da parte docente e da coordenação aos alunos para participarem } \\
\text { de programas de apoio pedagógico e de atividades extraclasse; Orientação } \\
\text { sobre a grade curricular antes da efetivação da matrícula. }\end{array}$ & \\
\hline - Orientação vocacional. & Dias; Theóphilo; Lopes (2010) \\
\hline - Oferta de monitorias/atendimento extraclasse pelos professores. & $\begin{array}{l}\text { Kruger Júnior et al. (2011); } \\
\text { Diogo et al. (2016) }\end{array}$ \\
\hline $\begin{array}{l}\text { - Realização de atividades integrativas em busca de fortalecer o vínculo } \\
\text { aluno-professor. Ex.: festas, jantares comemorativos, encontro de } \\
\text { confraternizações. }\end{array}$ & Tinto $(1975 / 93)$ \\
\hline $\begin{array}{l}\text { - Acompanhamento e Intervenção da coordenação nos problemas de ensino- } \\
\text { aprendizado desde as fases iniciais. }\end{array}$ & $\begin{array}{l}\text { Kruger Júnior et al. (2011); } \\
\text { Diogo et al. (2016) }\end{array}$ \\
\hline - Formação continuada do corpo docente. & $\begin{array}{l}\text { Andriola (2009); Dias; } \\
\text { Theóphilo; Lopes (2010) }\end{array}$ \\
\hline $\begin{array}{l}\text { - Oferta de infraestrutura adequada, tanto física (laboratórios, salas de aula, } \\
\text { equipamentos, biblioteca etc.), como humana (valorização dos professores, } \\
\text { remuneração para o desempenho das atividades de coordenação, auxílio de } \\
\text { monitores/estagiários em salas com maior número de alunos etc.). }\end{array}$ & $\begin{array}{l}\text { Andriola (2009); Dias; } \\
\text { Theóphilo; Lopes (2010); Diogo } \\
\text { et al. (2016) }\end{array}$ \\
\hline - Estrutura curricular flexível. & $\begin{array}{l}\text { Andriola (2009); Dias; } \\
\text { Theóphilo; Lopes (2010) }\end{array}$ \\
\hline $\begin{array}{l}\text { - Reforma da grade curricular: ampliação da carga horária de disciplinas } \\
\text { com maior índice de reprovação; não oferta de disciplinas consideradas } \\
\text { pesadas ou complexas no mesmo período; disponibilização das disciplinas } \\
\text { em todos os semestres. }\end{array}$ & $\begin{array}{l}\text { Andriola (2009); Dias; } \\
\text { Theóphilo; Lopes (2010); } \\
\text { Kruger Júnior et al. (2011); } \\
\text { Diogo et al. (2016) }\end{array}$ \\
\hline $\begin{array}{l}\text { - Oferta de atividades de integração dos discentes (Ex.: recepção aos } \\
\text { ingressantes; visitas de coordenadores às salas de aula etc.). }\end{array}$ & Tinto $(1975 / 93)$ \\
\hline $\begin{array}{l}\text { - Estímulo para que haja integração à universidade e à comunidade } \\
\text { acadêmica. }\end{array}$ & $\begin{array}{l}\text { Tinto (1975/93); Bueno (1993); } \\
\text { Silva Filho et al. (2007); Dias; } \\
\text { Theóphilo; Lopes (2010) }\end{array}$ \\
\hline
\end{tabular}

Fonte: Organizado pelos autores.

\section{METODOLOGIA}

Esta pesquisa classifica-se como descritiva, sendo quantitativa quanto à abordagem. A coleta de dados foi feita por meio de um levantamento mediante a aplicação de questionários aos coordenadores de Cursos de Ciências Contábeis brasileiros. A escolha das IES contemplou aquelas que apresentavam o cadastro no e-MEC, estavam em atividade e ofertavam o curso, configurando-se a população do estudo, em novembro de 2016, em 1.481 IES.

O questionário foi construído alinhado à teoria do abandono institucional de Tinto (1975/1993), que analisa o processo de evasão dos discentes em dois momentos: préuniversitário (atributos pré-ingresso e metas e compromissos) e universitário (experiências institucionais, integração acadêmica e social e metas e compromissos). Para a sua elaboração, foi feito, primeiramente, um levantamento bibliográfico dos estudos que analisaram as causas e as estratégias de para minimizar a evasão/discente. Após a identificação das variáveis, procedeu-se à elaboração das questões, direcionando-as aos coordenadores, conforme os grupos e subgrupos do modelo longitudinal do abandono institucional (TINTO, 1993).

A estruturação do questionário foi disposta em quatro seções. A primeira apresentou a pesquisa, seu objetivo e contribuições, bem como o termo de consentimento. Na segunda seção, 
foi feita a caracterização dos respondentes e das IES. A terceira seção contemplou oito questões de múltipla escolha sobre as estratégias adotadas pela instituição a fim de minimizar a evasão. $\mathrm{Na}$ última seção, foram apresentadas quatorze questões assertivas tratavam de ações da instituição relacionadas à evasão. Nessa seção, os participantes deveriam atribuir notas de $0 \mathrm{a}$ 10, sendo 0 para discordância total e 10 , para concordância total, sendo permitidas notas fracionadas.

Antes da aplicação do questionário, foi realizado um pré-teste com três coordenadores de cursos de graduação na área de negócios, tendo sido sugeridos alguns ajustes na descrição das questões, os quais foram incorporados ao instrumento.

Para a coleta de dados, foram feitos três contatos intercalados em um período de 10 dias, via e-mail da instituição/coordenador, com o convite para participar da pesquisa, bem como com a apresentação do link do questionário para preenchimento na Plataforma Google. Após os três envios e finalizada a coleta, a amostra ficou composta por 155 participantes, correspondendo a uma representação de $10,47 \%$ da população.

Para a análise dos dados, foram utilizadas: (a) a estatística descritiva, para identificar as principais características dos participantes da pesquisa; (b) comparações entre proporções por intermédio de um teste $\chi^{2}$ de comparações múltiplas entre proporções, conforme descrito em Biase e Ferreira (2009); (c) comparações de médias por meio do teste de Kruskal-Wallis, que possibilita a comparação de, no mínimo, três amostras (grupos) independentes; e (d) teste Wilcoxon para comparação de duas amostras, pois as pressuposições (normalidade, homogeneidade e independência dos resíduos) do teste F da Análise de Variância (ANOVA) não foram satisfeitas. Esse teste permite averiguar se não há diferença entre os tratamentos ou se, pelo menos, dois tratamentos diferem entre si (CONOVER, 1999). Posteriormente, para identificar as estratégias significativas associadas aos índices de evasão, ajustou-se um modelo de regressão linear múltipla.

A adequação do modelo foi avaliada, observando-se os seguintes aspectos: (i) a qualidade do ajuste por meio do coeficiente de determinação $\left(R^{2}\right)$; (ii) multicolinearidade entre as variáveis explicativas por meio da análise dos fatores de inflação da variância $(V I F)$; (iii) pressuposições de normalidade, independência e homogeneidade de variâncias dos resíduos a partir dos testes de Shapiro-Wilk, Durbin-Watson e Bartlett, respectivamente. Para seleção das variáveis, adotou-se o critério de Backward ("passo atrás"). Esse procedimento caracteriza-se por incorporar, inicialmente, todas as variáveis auxiliares em um modelo de regressão linear múltipla, bem como por percorrer etapa, nas quais uma variável, por vez, pode vir a ser eliminada. Se, em uma dada etapa, não houver eliminação de alguma variável, o processo é então interrompido e as variáveis restantes definem o modelo final (CHARNET et al., 2008). Para decidir sobre a eliminação ou não da variável, adotou-se o teste F parcial:

$$
\frac{\left(S Q \operatorname{Re} g^{c}-S Q \operatorname{Re} g^{r}\right)}{\hat{\sigma}^{2}} \sim F_{(\alpha, 1, n-p)}
$$

Sendo $S Q R_{e g}^{c}$ e $\hat{\sigma}^{2}$ calculadas sob o modelo completo e $S Q R_{e g}^{r}$ calculada sob o modelo reduzido. A estatística (1) testa a contribuição da variável após a inclusão das demais. Assim, a contribuição é significante se o valor da estatística for maior que um quantil especificado da distribuição $F$ com 1 e (n-p) graus de liberdade, sendo $p$ o número de parâmetros do modelo completo (CHARNET et al., 2008).

O método adotado para estimação dos parâmetros do modelo foi o Mínimos Quadrados Ordinários, tendo sido as análises implementadas no freeware R (R DEVELOPMENT CORE TEAM, 2016). 

A EVASÃO

\section{ANÁLISE E DISCUSSÃO DOS RESULTADOS}

\subsection{Análise Descritiva}

Após o envio dos questionários, foram recebidas 157 respostas. Desse total, duas foram invalidadas por irregularidades no preenchimento, obtendo-se assim uma amostra final de 155 coordenadores de curso de Ciências Contábeis de todas as regiões brasileiras. As informações acerca do perfil desses coordenadores são apresentadas na Tabela 1.

Tabela 1: Caracterização dos Coordenadores e das IES

\begin{tabular}{|c|c|c|}
\hline Variável & Possibilidade de Resposta & Quantidade (\%) \\
\hline \multirow{2}{*}{ Gênero } & Masculino & 64,5 \\
\hline & Feminino & 35,5 \\
\hline \multirow{3}{*}{ Idade } & Até 40 anos & 33,5 \\
\hline & De 41 a 50 anos & 39,4 \\
\hline & Acima de 50 anos & 27,1 \\
\hline \multirow{4}{*}{ Titulação } & Graduação & 0,6 \\
\hline & Especialização & 26,5 \\
\hline & Mestrado & 58,1 \\
\hline & Doutorado & 14,8 \\
\hline \multirow{2}{*}{ Categoria Administrativa } & Pública & 16,8 \\
\hline & Privada & 83,2 \\
\hline \multirow{3}{*}{ Organização Acadêmica } & Faculdade & 54,1 \\
\hline & Universidade & 26,5 \\
\hline & Centro Universitário & 19,4 \\
\hline \multirow{4}{*}{ Tempo no Cargo de Coordenador } & Até 5 anos & 67,7 \\
\hline & De 6 a 10 anos & 21,3 \\
\hline & De 11 a 20 anos & 9,7 \\
\hline & Acima de 20 anos & 1,3 \\
\hline \multirow{5}{*}{ Região da IES } & Sudeste & 40,6 \\
\hline & Sul & 27,1 \\
\hline & Nordeste & 13,6 \\
\hline & Centro Oeste & 11,6 \\
\hline & Norte & 7,1 \\
\hline \multirow{3}{*}{ Turno de oferecimento do curso } & Integral & 1,9 \\
\hline & Noturno & 81,3 \\
\hline & Integral, Noturno e Matutino & 16,7 \\
\hline \multirow{4}{*}{ Porcentagem de Evasão nas IES } & Até $5 \%$ & 18,4 \\
\hline & De $5 \%$ a $10 \%$ & 22,4 \\
\hline & De $10 \%$ a $20 \%$ & 32 \\
\hline & Acima de $20 \%$ & 27,2 \\
\hline
\end{tabular}

Fonte: Dados da Pesquisa.

Observa-se que, dos 155 coordenadores, $64,5 \%$ são do sexo masculino e que a maioria $(67,7 \%)$ não tem mais de 5 anos de experiência no cargo. Com relação à idade e à titulação, verifica-se que $1 / 3$ deles $(33,5 \%)$ têm idade até 40 anos e $27,1 \%$ não tem titulação stricto sensu. Verifica-se ainda que a maioria dos coordenadores investigados são mestres.

Quanto às IES às quais os respondentes estão vinculados, identificou-se que as regiões Sudeste e Sul tiveram uma representação superior às demais regiões, com cerca de 40,6\% e 
$27,1 \%$, respectivamente, sendo $83,2 \%$ das IES da rede privada e $54,1 \%$ são organizadas como faculdades. Pode-se notar também que: 40,8\% dos respondentes mencionaram haver índices de evasão no Curso de Ciências Contábeis inferiores a 10\%; 32\% das IES apresentam índices de $10 \%$ a $20 \%$ de evasão e $27,2 \%$ têm índices de evasão acima de $20 \%$. A taxa média de evasão manifestada pelos respondentes foi de $17,25 \%$. É importante salientar que esse número é inferior àqueles divulgados pela SEMESP (2015), segundo a qual os índices chegaram a 24,9\% no ensino presencial e 28,8\%, no Ensino a Distância.

A Tabela 2 ilustra as taxas médias de evasão manifestadas por categoria administrativa e região.

Tabela 2: Taxas de Evasão nas IES por Categoria Administrativa e Região

\begin{tabular}{ccc}
\hline Variável & Descrição & Percentual (\%) \\
\hline \multirow{2}{*}{ Categoria Administrativa } & Pública & $21,0^{\mathrm{a}}$ \\
& Particular & $17,0^{\mathrm{a}}$ \\
\hline \multirow{3}{*}{ Região } & CO & $17,0^{\mathrm{a}}$ \\
& $\mathrm{NE}$ & $20,0^{\mathrm{a}}$ \\
& NO & $20,0^{\mathrm{a}}$ \\
& SE & $16,0^{\mathrm{a}}$ \\
& SUL & $18,0^{\mathrm{a}}$ \\
\hline
\end{tabular}

Taxas médias, nas colunas, seguidas da mesma letra minúscula sobrescrita não diferem estatisticamente entre si pelo teste de Wilcoxon e Kruskal-Wallis, respectivamente, ao nível de significância de 5\%.

Fonte: Dados da Pesquisa.

Verifica-se que as taxas médias de evasão das instituições públicas são estatisticamente similares às das instituições particulares, conforme revela o teste Wilcoxon. Esse resultado diverge daqueles apresentados pela SEMESP (2015), pois a taxa de evasão dos cursos presenciais nas instituições públicas, segundo a SEMESP (2015), foi de 17,8\%, enquanto a taxa média da rede privada foi de $27,4 \%$.

Verificou-se ainda, por meio do teste Kruskal-Wallis, que não houve diferença significativa entre as taxas médias de evasão das regiões brasileiras. Todavia, estudos anteriores apontam que as regiões Sul e Sudeste apresentaram taxas médias de evasão menores que as demais regiões (SEMESP, 2015).

$\mathrm{Na}$ terceira seção do questionário, indagou-se aos coordenadores de curso quais as estratégias adotadas a fim de minimizar a evasão nas respectivas instituições. As questões tratavam das ações de combate à evasão no período pré-universitário e no período universitário. $\mathrm{Na}$ Tabelas 3, são apresentas as estratégias/ações relacionadas ao período pré-universitário e o percentual das IES que declararam utilizar algum procedimento nesse sentido.

Nota-se, conforme mostra a Tabela 3, que a maioria das IES realiza atividades de combate à evasão, o que demonstra a preocupação das mesmas em conter/diminuir os índices de saída-discente. No tocante às ações de orientação vocacional, os resultados do teste de comparações múltiplas de proporções indicaram que os itens "oferta de disciplinas aos alunos antes do ingresso" (90\%), "divulgação sobre o curso e áreas de atuação em meios informativos" (79\%) e "visitas às escolas de ensino médio" (76\%) são significativamente maiores que os demais. Importante destacar a relevância dessas ações, uma vez que a incompatibilidade vocacional é identificada como fator de evasão nas pesquisas de Dias, Theóphilo e Lopes (2010), Krüger Júnior et al. (2011) e Diogo et al. (2016).

Dentre os auxílios econômicos relacionados na Tabela 3, o teste de comparações múltiplas de proporções evidenciou que a maioria das IES oferece bolsa ou descontos nas mensalidades escolares (65\%) e financiamento por parte da IES para pagamento das mensalidades (54\%), não havendo diferença significativa entre essas duas proporções. Os 

A EVASÃO

demais tipos de bolsas (bolsas de auxílio moradia, alimentação e transporte) são ofertados em menor proporção pelas IES, não apresentando diferença significativa entre elas ao nível de 5\% (letras minúsculas iguais). Para Dias, Theóphilo e Lopes (2010) e Cunha et al. (2015), essas são formas de diminuir a evasão dos estudantes que se encontram em situação de vulnerabilidade socioeconômica. Já para suprir as deficiências da formação básica, são comuns iniciativas como: cursos de nivelamento (66\%), monitorias ou atendimento extraclasse (60\%) e apoio pedagógico (56\%). Em se tratando desses tipos de ações, não houve diferença significativa entre as proporções, isto é, os resultados indicam que as IES promovem tais ações em igual proporção para combater a evasão. Entretanto, quanto a essas iniciativas, foi evidenciada uma diferença significativa quando comparadas com o oferecimento de reforço em disciplinas de maior reprovação e a não oferta do reforço ao longo do curso. A esse respeito, Bueno (1993) e Diogo et al. (2016) destacam a relevância dessas iniciativas e atribuem tais deficiências à precária formação escolar básica brasileira.

Tabela 3: Estratégias adotadas para minimizar a evasão no período pré-universitário

\section{Atributos Pré-ingresso}

Q1. Ações de orientação vocacional:

Oferta de disciplinas aos alunos antes do ingresso;

$90,30 \%^{\mathrm{a}}$

Divulgação sobre o curso e áreas de atuação em meios informativos;

$79,40 \%$ ab

Visitas às escolas de ensino médio;

$76,10 \%$ ab

Seminários ou palestras;

$70,30 \%$ b

Serviço de orientação vocacional;

$27,10 \%$ c

Não realiza nenhuma ação de orientação vocacional.

$7,10 \%$ d

\begin{tabular}{lc}
\hline Q2. Auxílios econômicos: & \\
\hline Bolsa/desconto nas mensalidades escolares; & $65,20 \%^{\mathrm{a}}$ \\
Financiamento da IES para pagamento das mensalidades; & $54,20 \%^{\mathrm{a}}$ \\
Bolsa/auxílio moradia; & $11,60 \%^{\mathrm{b}}$ \\
Bolsa alimentação; & $10,30 \%^{\mathrm{b}}$ \\
Não oferece auxílio econômico; & $8,40 \%^{\mathrm{b}}$ \\
Bolsa/auxílio transporte; & $7,70 \%^{\mathrm{b}}$ \\
Bolsa creche. & $0,60 \%^{\mathrm{b}}$
\end{tabular}

Q3. Reforços para suprir deficiências da formação básica do aluno:

Cursos de nivelamento;

$66,50 \%$

Monitorias ou atendimento extraclasse;

$60,00 \%$ a

Apoio pedagógico;

$56,10 \%$ a

Reforço em disciplinas de maior reprovação;

Não oferece reforço escolar para suprir deficiências da formação básica.

$9,00 \%$ b

Metas e Compromissos

Q5. Eventos informativos:

Palestras com profissionais do mercado;

$94,80 \%^{\mathrm{a}}$

Visitas técnicas;

$75,50 \%$ b

Feiras profissionais;

$58,70 \%$ bc

Orientações sobre recrutamento profissional;

$43,90 \%{ }^{c}$

Não realiza eventos sobre mercado profissional.

$2,60 \%$ d

Proporções nas colunas, seguidas da mesma letra minúscula sobrescrita, não diferem estatisticamente entre si pelo teste de comparações múltiplas, ao nível de significância de $5 \%$.

Fonte: Dados da Pesquisa.

Os eventos informativos também são bastante comuns nas instituições às quais se vinculam os respondentes. Destaca-se em maior proporção a oferta de palestras com 
profissionais de mercado que ocorrem em, aproximadamente, 95\% da amostra, seguidas por eventos como visitas técnicas e feiras, com $75 \%$ e 59\%, respectivamente. Para Krüger Júnior et al. (2011) e Diogo et. al. (2016), programas como esses auxiliam os estudantes a estabelecerem a ligação entre o ensino teórico e o mercado de trabalho.

Quanto às estratégias/ações relacionadas ao período universitário que as IES declararam utilizar, têm-se os seguintes resultados apresentados na Tabela 4.

Tabela 4: Estratégias adotadas para minimizar a evasão no período universitário

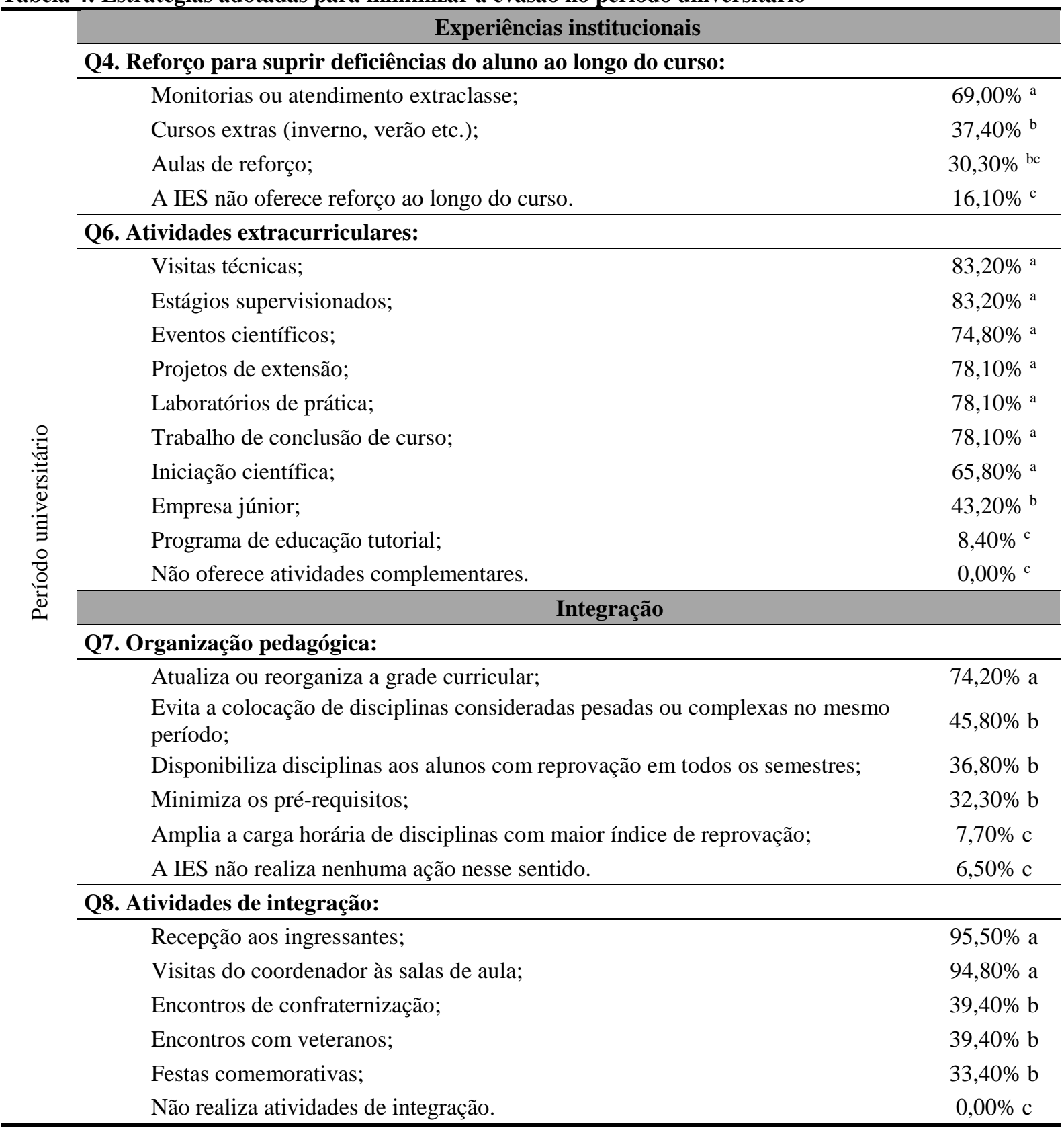

Proporções nas colunas, seguidas da mesma letra minúscula sobrescrita, não diferem estatisticamente entre si pelo teste de comparações múltiplas, ao nível de significância de 5\%.

Fonte: Dados da Pesquisa.

De acordo com a Tabela 4, no que tange ao reforço para suprir deficiências do aluno ao longo do curso, conforme sugerido por Andriola (2009) e Diogo et al. (2016), a estratégia utilizada em maior proporção foi monitorias ou atendimentos extraclasse (69\%), seguida por cursos extras, que são ofertados por $37,4 \%$ das instituições pesquisadas. 

A EVASÃO

As atividades extracurriculares também são ofertadas pela maioria das instituições, o que se dá em praticamente todas com bastante intensidade, não apresentando a maioria das atividades diferenças significativas entre as proporções. No que se refere às ações relativas à organização pedagógica promovida pelas instituições, destaca-se a atualização da grade curricular $(74 \%)$. Já com relação às atividades de integração, destacam-se a recepção aos ingressantes (95\%) e as visitas do coordenador às salas de aula (95\%), não havendo diferença significativa entre elas ao nível de 5\%. As demais atividades ocorrem com menor intensidade. Tinto (1975) enfatiza a importância de serem desenvolvidas atividades de integração do discente à comunidade para ampliar o comprometimento com o curso, diminuindo, assim, as chances de evasão.

Percebe-se ainda que as ações adotadas em maior grau pelas IES estão direcionadas à orientação profissional, à adaptação do estudante à vida universitária, à integração do discente à instituição e à comunidade e à sua condição financeira. De acordo com Tinto (1975/93); Bueno (1993); Silva Filho et al. (2007); Dias; Theóphilo; Lopes (2010), essas são variáveis determinantes na vida acadêmica do discente.

Tabela 5: Ações Didático-Pedagógicas

\begin{tabular}{|c|c|c|c|c|c|c|}
\hline Questões Assertivas & $\mathbf{N}$ & Média & Mediana & $\begin{array}{l}\text { Desvio } \\
\text { Padrão }\end{array}$ & Mínimo & Máximo \\
\hline \multicolumn{7}{|c|}{ Acompanhamento e intervenção da coordenação referente: } \\
\hline $\begin{array}{l}\text { A1. Aos problemas de ensino-aprendizado nas } \\
\text { fases iniciais do curso. }\end{array}$ & 141 & 8,46 & 9 & 1,89 & 0 & 10 \\
\hline $\begin{array}{l}\text { A2. Às dificuldades de ensino e aprendizagem do } \\
\text { discente no decorrer do curso. }\end{array}$ & 144 & 8,19 & 8,5 & 1,93 & 0 & 10 \\
\hline $\begin{array}{l}\text { A3. Aos níveis de satisfação/motivação dos } \\
\text { alunos com o curso. }\end{array}$ & 144 & 8,34 & 9 & 1,83 & 0 & 10 \\
\hline $\begin{array}{l}\text { A4. À frequência dos alunos às aulas (para reduzir } \\
\text { os níveis de absenteísmo). }\end{array}$ & 147 & 6,99 & 7 & 2,68 & 0 & 10 \\
\hline \multicolumn{7}{|l|}{ Ações exercidas pela coordenação: } \\
\hline $\begin{array}{l}\text { A5. Divulgação do Projeto Pedagógico do Curso } \\
\text { aos alunos, inclusive aos ingressantes. }\end{array}$ & 147 & 7,74 & 8 & 2,73 & 0 & 10 \\
\hline A6. Orientação aos alunos para se matricularem. & 150 & 7,87 & 9 & 2,78 & 0 & 10 \\
\hline A7. Flexibilização da grade curricular. & 147 & 5,41 & 6 & 3,66 & 0 & 10 \\
\hline \multicolumn{7}{|l|}{ Ações exercidas pela instituição: } \\
\hline $\begin{array}{l}\text { A9. Autonomia da coordenação para tomada de } \\
\text { decisão. }\end{array}$ & 146 & 7,03 & 8 & 2,22 & 0 & 10 \\
\hline $\begin{array}{l}\text { A10. Apoio para a formação didático-pedagógica } \\
\text { aos docentes (cursos de extensão, cursos de } \\
\text { aperfeiçoamento, palestras etc.). }\end{array}$ & 149 & 7,58 & 8 & 2,73 & 0 & 10 \\
\hline $\begin{array}{l}\text { A11. Apoio para a formação acadêmica } \\
\text { continuada (mestrado/doutorado) aos docentes, } \\
\text { como: flexibilidade de horários, licença para se } \\
\text { qualificar, auxílio financeiro etc. }\end{array}$ & 152 & 6,47 & 7 & 3,24 & 0 & 10 \\
\hline $\begin{array}{l}\text { A13. Apoio psicológico aos estudantes para } \\
\text { prevenir evasão. }\end{array}$ & 146 & 7,42 & 8 & 2,99 & 0 & 10 \\
\hline $\begin{array}{l}\text { A14. Programas de monitoramento e intervenção } \\
\text { em relação à evasão no curso. }\end{array}$ & 150 & 6,29 & 7 & 3,19 & 0 & 10 \\
\hline \multicolumn{7}{|l|}{ Estrutura física e humana da IES: } \\
\hline $\begin{array}{l}\text { A8. Docentes com experiência profissional nos } \\
\text { conteúdos que lecionam. }\end{array}$ & 143 & 8,88 & 9 & 1,32 & 5 & 10 \\
\hline $\begin{array}{l}\text { A12.Infraestrutura adequada (laboratórios de } \\
\text { informática, salas de aulas equipadas, recursos } \\
\text { áudio visuais, bibliotecas atualizadas etc.). }\end{array}$ & 144 & 8,24 & 9 & 1,79 & 2 & 10 \\
\hline
\end{tabular}

Fonte: Dados da Pesquisa. 
Já em relação às ações com menor grau de adoção, verificou-se, no período préuniversitário, serviço de orientação vocacional e o reforço em disciplinas com maior reprovação. Bardagi e Hutz (2009) identificaram em seu estudo que a questão vocacional tem forte influência no abandono do ensino superior, principalmente, em virtude de a decisão pela escolha profissional em nosso país ser tomada precocemente, ou seja, antes do ingresso no ensino superior. Os estudantes, por não receberem apoio necessário para a compreensão da vocação profissional, fazem suas escolhas influenciados por imposição familiar (BARDAGI, 2007; DIAS; THEÓPHILO; LOPES, 2010; CUNHA; NASCIMENTO; DURSO, 2016).

$\mathrm{Na}$ Tabela 5, são apresentadas as questões que abordaram ações didático-pedagógicas adotadas pela instituição.

Destaca-se que as IES estudadas apresentam em sua estrutura docentes que têm experiência profissional nos conteúdos que lecionam (média de 8,88), o que não indica necessariamente qualificação pedagógica. Por sua vez, Silva (2013) aborda que, no decorrer da graduação, é comum a presença de professores com baixa qualificação pedagógica. Segundo o autor, tal fato contribui para a desmotivação dos estudantes e influencia o aumento da evasão. Nesse sentido, seria necessário apoio da IES para a formação docente, podendo tal afirmativa se apoiar na baixa taxa média de respostas para as questões relacionadas com os aspectos de apoio à formação pedagógica (apoio à formação continuada, flexibilidade de horários, licença para qualificação e auxílio financeiro).

Verificou-se, ainda, uma baixa média das respostas em relação às ações da coordenação para maior flexibilização da grade horária (5,41). Os autores Andriola (2009); Dias, Theóphilo e Lopes (2010); Diogo et al. (2016) indicam como estratégias de combate à evasão a reforma da grade curricular, como, por exemplo, evitar a colocação de disciplinas consideradas pesadas ou complexas no mesmo período. Adicionalmente, Andriola (2009) reforça que o papel dos coordenadores é essencial para apoiar os alunos com ações de reforço para suprir deficiências da formação básica (período pré-universitário).

$\mathrm{Na}$ segunda etapa de análise dos dados deste estudo, foi proposta a aplicação da regressão, apresentando-se, no próximo tópico, os resultados encontrados.

\subsection{Análise de Regressão Múltipla}

Para o ajuste do modelo de regressão linear múltipla, a taxa de evasão foi considerada como variável dependente. As demais variáveis foram assumidas como independentes, sendo elas: gênero, tempo de coordenação, titulação, idade, turno, tempo de oferecimento do curso, organização acadêmica da IES, categoria administrativa da IES, região, quantidade de alunos, as estratégias elencadas na Tabela 3 e 4 e as ações didático-pedagógicas listadas na Tabela 5.

Inicialmente, antes de propor o ajuste do modelo, foi realizado o estudo de multicolinearidade, conforme recomenda a literatura de Draper e Smith (1998). As variáveis que apresentaram valores do VIF maiores que 4, conforme recomendam os autores, foram excluídas da análise, quais sejam: Q2_A; Q2_B; Q5_C; Q6_A; A1; A2; A4; A11, e categoria administrativa. Em seguida, com as variáveis restantes, ou seja, excluindo-se as variáveis que apresentam VIF acima do valor 4, ajustou-se o modelo de regressão linear múltipla por meio do critério de "backward" e do teste $F$ parcial. Na Tabela 6 , é apresentado o ajuste final do modelo. As variáveis listadas acima e que não se apresentam na Tabela 6 foram não significativas ao nível de $10 \%$.

Com base na Tabela 6, ao nível de significância de $10 \%$, todos os parâmetros são significativos e todas as pressuposições acerca dos resíduos foram atendidas. Além disso, é possível observar que não há presença de multicolinearidade, pois todos os VIF's são inferiores a 4. 
ESTRATÉGIAS DAS COORDENAÇÕES DOS CURSOS DE CIÊNCIAS CONTÁBEIS PARA COMBATER A EVASÃO

Tabela 6: Resultados do ajuste do modelo de regressão para predição da variável VEvasão

\begin{tabular}{|c|c|c|c|c|c|c|}
\hline Parâmetros & Estimativa & Erro Padrão & $\mathrm{t}$ & valor $\mathrm{p}$ & VIF & $\mathrm{R}^{2}$ \\
\hline$\beta_{0}$ & 0,255 & 0,074 & 3,464 & 0,001 & --- & 0,5031 \\
\hline$\beta_{\mathrm{A} 2}$ & $-0,011$ & 0,005 & $-2,083$ & 0,040 & 1,482 & \\
\hline$\beta_{\mathrm{A} 4}$ & $-0,018$ & 0,004 & $-4,375$ & $<0,000$ & 1,748 & \\
\hline$\beta_{\mathrm{A} 6}$ & $-0,009$ & 0,003 & $-2,684$ & 0,008 & 1,273 & \\
\hline$\beta_{\mathrm{A} 8}$ & 0,021 & 0,007 & 3,135 & 0,002 & 1,246 & \\
\hline$\beta_{\text {Genero }}$ & 0,033 & 0,019 & 1,732 & 0,086 & 1,250 & \\
\hline$\beta_{\mathrm{D}_{-} \text {Turno }}$ & 0,047 & 0,024 & 1,949 & 0,054 & 1,157 & \\
\hline$\beta_{\mathrm{Q} 1 \_\mathrm{C}}$ & $-0,073$ & 0,031 & $-2,276$ & 0,025 & 1,283 & \\
\hline$\beta_{\mathrm{Q} 2 \mathrm{C}}$ & $-0,057$ & 0,032 & $-1,757$ & 0,082 & 1,092 & \\
\hline$\beta_{\mathrm{Q} 2 \_\mathrm{D}}$ & $-0,035$ & 0,019 & $-1,822$ & 0,071 & 1,311 & \\
\hline$\beta_{\mathrm{Q} 3 \_\mathrm{A}}$ & 0,047 & 0,020 & 2,323 & 0,022 & 1,421 & \\
\hline$\beta_{\mathrm{Q} 3 \_\mathrm{D}}$ & 0,044 & 0,024 & 1,814 & 0,073 & 2,077 & \\
\hline$\beta_{\mathrm{Q} 4 \_\mathrm{B}}$ & $-0,061$ & 0,024 & $-2,505$ & 0,014 & 1,956 & \\
\hline$\beta_{\mathrm{Q} 4 \mathrm{C}}$ & 0,045 & 0,020 & 2,273 & 0,025 & 1,357 & \\
\hline$\beta_{\mathrm{Q6} \_\mathrm{I}}$ & $-0,052$ & 0,022 & $-2,403$ & 0,018 & 1,271 & \\
\hline$\beta_{\mathrm{Q7} \_\mathrm{A}}$ & 0,120 & 0,031 & 3836 & $<0,000$ & 1,122 & \\
\hline$\beta_{\mathrm{Q} 8 \mathrm{C}}$ & $-0,042$ & 0,019 & $-2,255$ & 0,026 & 1,296 & \\
\hline \multicolumn{7}{|c|}{ Pressuposições resíduos } \\
\hline \multirow{2}{*}{ Testes } & Normalidade & valor $\mathrm{p}$ & Homogeneidade & valor $\mathrm{p}$ & Independência & valor $\mathrm{p}$ \\
\hline & Shapiro-Wilk & 0,934 & Bartlett & 0,593 & Durbin-Watson & 0,136 \\
\hline
\end{tabular}

Fonte: Dados da Pesquisa.

O teste de regressão constatou uma relação inversamente proporcional das variáveis A2, A4 e A6 com a variável evasão, o que aponta o menor índice de evasão nas IES em que a coordenação faz o acompanhamento e a intervenção em relação às dificuldades de ensinoaprendizagem ao longo do curso, que oferece orientação aos alunos no ato de matrícula e que estimula os alunos a frequentarem as aulas. Essas ações didático-pedagógicas, que interferem positivamente na redução das taxas de evasão e já haviam sido apontadas por Tinto (1975), estimulam a integração do aluno com a instituição.

Verificou-se ainda que há associação positiva da variável A8 (Docentes com experiência profissional) com a variável evasão. Â primeira vista, pode parecer contraintuitivo essa associação. Todavia, é possível supor que os docentes com mais experiência profissional sejam aqueles com menor qualificação acadêmica (doutorado/mestrado) e com menor número de pesquisas, que são variáveis comprovadamente associadas ao desempenho acadêmico (MIRANDA et al., 2015). Além disso, a atuação no mercado e na academia, concomitantemente, pode gerar sobrecarga para o profissional, afetando a qualificação pedagógica. Segundo Silva (2013), a ausência de formação docente em aspectos pedagógicos possibilitará fragilidades na apresentação dos conceitos teóricos e, consequentemente, na relação com a prática, desmotivando os estudantes e influenciando no aumento da evasão.

Identificou-se também uma associação positiva entre coordenadores do gênero masculino e as taxas de evasão nas IES, ou seja, os cursos coordenados por homens tendem a apresentar maiores taxas de evasão. Há que se destacar que o percentual de mulheres atuando como coordenadoras nos cursos pesquisados é baixa (35,5\%), sendo elas, em geral, mais jovens e com titulação stricto sensu. Esses atributos, talvez, sejam responsáveis pelas menores taxas de evasão. Todavia, novas pesquisas são necessárias para explicar efetivamente esse fenômeno.

Quanto ao turno de oferta do curso, as instituições que declaram oferecer o curso no período noturno apresentaram um índice de evasão maior do que aquelas que fazem essa oferta no período integral. O estudo de Dias, Theóphilo e Lopes (2010) identificou que a maioria dos 
estudantes evadidos eram do período noturno. De fato, outras pesquisas evidenciam que estudantes do turno noturno têm mais dificuldades para se dedicarem aos estudos, pois, via de regra, já estão no mercado de trabalho (MIRANDA et al. 2015; DIAS; THEÓPHILO; LOPES, 2010; KRÜGER JÚNIOR et al., 2011).

A oferta aos alunos de disciplinas ligadas às várias áreas do ensino superior antes do ingresso é uma das sugestões dadas pelos coordenadores da Universidade Federal do Ceará, participantes do estudo de Andriola (2009), como uma forma de apresentar o curso aos estudantes que estão prestes a ingressar no ensino superior. De acordo com a pesquisa de Dias, Theóphilo e Lopes (2010), a maioria dos alunos evadiu por falta de conhecimento do curso. Portanto, decorrente do observado nos estudos anteriores descritos na revisão de literatura, esperava-se dessa variável (Q1_C) o comportamento inversamente proporcional à evasão apontado pelo teste.

Os resultados identificados em relação às variáveis Q2_C (Bolsa/auxílio transporte) e Q2_D (Bolsa/desconto nas mensalidades escolares) foram similares aos encontrados nos estudos realizados por Dias, Theóphilo e Lopes (2010) e Krüger Júnior et al. (2011). Os autores identificaram que o perfil socioeconômico do estudante pesa na sua decisão de evadir. Importante destacar que as IES que mais disponibilizam bolsas de auxílio e/ou descontos nas mensalidades escolares tendem a apresentar menores taxas de evasão.

Constatou-se também que as IES que empreendem ações para suprir as deficiências na formação básica do aluno (ao ingresso no curso), como cursos de nivelamento, monitorias, atendimento extraclasse e cursos extras (Q3_A, Q3_D e Q4_C), apresentavam os maiores índices de evasão. Para Diogo et al. (2016), isso ocorre, pois os alunos, ao ingressarem no ensino superior, sem consciência das diferenças entre esse e o ensino médio, sentem-se despreparados e inaptos, o que dificulta a sua integração acadêmica, podendo levá-los a se evadirem (TINTO, 1975/93). A esse respeito, há que se pensar que, além de essas estratégias não estarem sendo eficazes, a própria base deficiente do aluno pode ser uma das principais causas da evasão. Em contraponto, as instituições que declararam oferecer monitorias ou atendimento extraclasse, referentes disciplinas propostas na grade curricular, para suprir deficiências do aluno ao longo do curso (Q4_B) tiveram um menor índice de evasão.

Outro fator de associação positiva com a evasão foi a carga horária de disciplinas com maior índice de reprovação (Q7_A), ou seja, quanto maior a carga-horária dessas disciplinas, maiores as taxas de evasão. Assim, aumentar a carga horária de uma disciplina considerada complexa desmotiva o estudante, afetando negativamente o seu desempenho. Nesse sentido, indica-se a reforma da grade curricular, evitando, inclusive, inserção de disciplinas consideradas pesadas ou complexas no mesmo período (ANDRIOLA, 2009; DIAS; THEÓPHILO; LOPES, 2010; DIOGO et al., 2016).

Por fim, identificou-se que as IES do estudo que exigem o trabalho de conclusão de curso (Q6_I) e que organizam encontros de confraternização (Q8_C) apresentam menores índices de evasão. Para Tinto (1975/93) e Krüger Júnior et al. (2011), isso acontece porque essas atividades promovem integração acadêmica e social do estudante e o estimulam a continuar no curso.

\section{CONCLUSÕES}

Considerando o objetivo proposto para o presente estudo, foram identificadas e analisadas as estratégias adotadas pelas IES para o curso de Ciências Contábeis com o propósito de minimizar a evasão. Os coordenadores pesquisados indicaram que: 40,8\% dos cursos apresentam índices de evasão inferiores a 10\%; 32\% têm índices de 10 a 20\% de evasão; e $27,2 \%$ têm índices de evasão acima de $20 \%$.

Percebe-se que as IES pesquisadas demonstram preocupação com a evasão e relatam empreender ações de combate à ocorrência desse fenômeno. $\mathrm{Na}$ investigação sobre as 

A EVASÃO

estratégias adotadas para minimizar a evasão, identificaram-se as ações relativas a fragilidades estudantis do período pré-universitário, como: orientação vocacional; oferta de disciplinas aos alunos antes do ingresso; divulgação sobre o curso e áreas de atuação em meios informativos; visitas às escolas de ensino médio; e seminários ou palestras sobre os cursos.

Importante destacar que os resultados deste estudo apontaram que, nas IES em que as coordenações oferecem orientações sobre os cursos aos alunos no ato de matrícula, o índice de evasão é menor. Tais achados propiciam reflexões sobre a necessidade de oferta de programas de orientação vocacional, que possam dar ao estudante alguns direcionamentos sobre os cursos, carreira profissional e a vida universitária.

Foram identificados também esforços empreendidos para suprir deficiências da formação básica do aluno, como: cursos de nivelamento, monitorias e apoio pedagógico. Constatou-se neste estudo que essas ações, de fato, apresentaram efetividade na redução dos índices de evasão, sinalizando que as IES estão no caminho certo.

Os alunos ingressam no ensino superior sem a consciência das suas diferenças se comparado ao ensino médio e, ao se depararem com disciplinas complexas, sentem a sensação de inaptidão, acarretando altas taxas de reprovação nas fases iniciais dos cursos (DIOGO et al., 2016). Torna-se relevante, então, o oferecimento pelas IES e professores de atividades com o objetivo de apresentar ao estudante as estratégias de aprendizagem que poderão ser adotadas no decorrer do processo de ensino e aprendizagem. Muitos estudantes desconhecem tais estratégias, o que afeta seu desempenho estudantil. Verificou-se também baixa oferta de auxílios econômicos, como bolsas de auxílio moradia, alimentação e transporte, mas, por outro lado, são proporcionados descontos e financiamentos para pagamento das mensalidades, no caso das IES particulares. Essas ações apresentaram comportamento esperado, conforme a literatura estudada, como forma de contribuir com a diminuição dos índices, o que sugere que a intensificação dessas ações pode contribuir para reduzir as taxas de evasão.

Já na etapa do período universitário, as principais estratégias adotadas para minimizar a evasão dizem respeito aos eventos informativos (palestras com profissionais do mercado e visitas técnicas), sendo indicadas também as atividades extracurriculares (projetos de extensão, eventos científicos, laboratórios de prática e estágio supervisionado). Em relação às ações para suprir deficiência da formação básica ou aquelas que surgirão ao longo do curso, a maior oferta ocorre somente em forma de monitorias ou atendimentos extraclasse. Verifica-se, ainda, uma baixa oferta de aulas de reforço e cursos extras, mas foram indicadas atividades de integração, como recepção aos ingressantes e visitas do coordenador às salas de aula. Essas ações mostraram-se efetivas para a redução das taxas de evasão, o que se deve ao fato de promoverem a integração acadêmica e social do discente ao ambiente universitário, influenciando-o nas suas metas e compromissos com a instituição (TINTO, 1975/93; BUENO, 1993; SILVA FILHO ET AL., 2007; DIAS, THEÓPHILO E LOPES, 2010).

Os achados deste estudo evidenciaram diversas variáveis apontadas no modelo proposto por Tinto (1993), conforme percepção dos coordenadores, em relação às estratégias adotadas para minimizar a evasão. Dentre essas estratégias, estão as ações adotadas no período préuniversitário, tratadas como causas externas, ou no período universitário, que são ações internas à instituição (TINTO, 1993; DIAS; THEÓPHILO; LOPES, 2010). Nesse sentido, os resultados sugerem que os gestores acadêmicos poderão direcionar as estratégias externas que visem ao apoio socioeconômico aos estudantes e ao melhor planejamento para o modelo didático pedagógico dos cursos com vistas a minimizar as dificuldades escolares dos estudantes. Em relação às ações internas, as IES deverão propor melhorias na sua infraestrutura, bem como a qualificação do corpo docente, além de assistência socioeducacional aos estudantes.

Em síntese, os resultados da regressão confirmaram que, nas IES em que a coordenação promove a integração acadêmica dos alunos, ocorre redução da evasão. Dentre as ações de integração, podem ser destacadas aquelas que se destinam ao acompanhamento e intervenção 
em relação às dificuldades de ensino-aprendizagem ao longo do curso, à frequência do aluno e também ao oferecimento de orientação sobre o curso no ato de matrícula. Verificou-se ainda que os cursos no turno noturno apresentam maior índice de evasão se comparados com os do período integral. Normalmente, a maioria dos alunos de Ciências Contábeis matriculados no curso noturno já está atuando no mercado de trabalho, o que influencia na dedicação aos estudos, podendo afetar na decisão de evasão. Sugere-se, nesse caso, que os docentes promovam a integração dos conteúdos programáticos do curso com a prática, assim, os estudantes trabalhadores terão maior envolvimento nas aulas, minimizando a ocorrência da evasão. Os testes indicaram também que as bolsas de auxílio financeiro e descontos nas mensalidades escolares oferecidas pelas IES reduzem as taxas de evasão, corroborando os estudos de Dias, Theóphilo e Lopes (2010) e Krüger Júnior et al. (2011). Os resultados evidenciaram ainda que a oferta de monitorias e o atendimento extraclasse para suprir deficiências do aluno ao longo do curso também minimizam a ocorrência do fenômeno da evasão.

Espera-se que este estudo contribua para as IES, coordenadores e docentes conhecerem as estratégias que poderão combater e/ou minimizar a evasão, seja por meio do acompanhamento aos alunos ou pela oferta do apoio necessário para evitar o abandono do curso. Ademais, as ações adotadas pelas IES que apresentam resultados positivos em relação à evasão podem servir de exemplo para que outras instituições utilizem procedimentos similares para minimizar esse tipo de ocorrência.

Os achados reforçam o modelo indicado por Tinto (1993). Segundo o autor, torna-se essencial manter o equilíbrio na integração acadêmico e social, caso contrário, poderão emergir a insatisfação e a desmotivação dos alunos, o que, consequentemente, causará a evasão do curso universitário.

Destaca-se, por fim, a necessidade de estudos acerca de ações de combate à evasão. Assim, sugere-se, para futuros estudos, investigar se as características demográficas do coordenador de curso, como gênero, idade, renda, dentre outras, afetam as taxas de evasão. Torna-se relevante também a realização de uma pesquisa qualitativa para explorar, com profundidade, as estratégias adotadas para minimizar a evasão na percepção dos coordenadores, docentes e estudantes.

\section{REFERÊNCIAS}

ANDRIOLA, W. Fatores associados à evasão discente na Universidade Federal do Ceará (UFC) de acordo com as opiniões de docentes e de coordenadores de cursos. Revista Iberoamericana sobre Calidad, Eficacia y Cambio en Educación, v. 7, n. 4, p. 342-355, 2009.

BAGGI, C. A. S.; LOPES, D. A. L. Evasão e avaliação institucional no ensino superior: uma discussão bibliográfica. Revista de Avaliação da Educação Superior, v. 16, n. 2, p. 355374, 2011.

BARDAGI, M. P. Evasão e comportamento vocacional de universitários: estudos sobre o desenvolvimento de carreira na graduação 2007. 242 f. (Tese) Doutorado em Psicologia Universidade Federal do Rio Grande do Sul - UFRGS, Rio Grande do Sul, 2007. Disponível em: <http://www.lume.ufrgs.br/handle/10183/10762>. Acesso em: 01 jan. 2017.

BARDAGI, M. P.; HUTZ, C. S. "Não havia outra saída": percepções de alunos evadidos sobre o abandono do curso superior. Psico-USF, v. 14, n. 1, p. 95-105, 2009. 
ESTRATÉGIAS DAS COORDENAÇÕES DOS CURSOS DE CIÊNCIAS CONTÁBEIS PARA COMBATER A EVASÃO

BIASE, N. G.; FERREIRA, D. F. Comparações múltiplas e testes simultâneos para parâmetros binomiais de k populações independentes. Revista Brasileira de Biometria, v. 27, p. 301-323, 2009.

BRASIL/MEC/SESU. Comissão especial de estudos sobre a evasão nas universidades públicas brasileiras. Brasília: ANDIFES/ABRUEM/SESU/MEC, 1996.

BRASIL. INSTITUTO NACIONAL DE ESTUDOS E PESQUISAS EDUCACIONAIS ANÍSIO TEIXEIRA (INEP). Censo da Educação Superior. Brasil: INEP, 2017. Disponível em: < http://portal.inep.gov.br/web/guest/censo-da-educacao-superior>. Acesso em: 18 out. 2018.

BUENO, J. L. O. A Evasão de Alunos. Paidéia, v. 25, n. 5, p. 9-16, 1993. Disponível em: <http://www.scielo.br/pdf/paideia/n5/02.pdf>. Acesso em: 01 jan. 2017.

CHARNET, R.; FREIRE, C. A. de L.; CHARNET, E. M. R.; BONVINO, H. Análise de modelos de regressão linear: com aplicações. 2. ed. São Paulo: Editora da Unicamp, 2008.

CONOVER, W. J. Practical nonparametric statistics. 3. ed. New York: J. Wiley, 1999.

CUNHA, J. V. A.; LUCA, M. M. M. de; LIMA, G. A. S. F.; CORNACCHIONE, E. B., Jr.; OTT, E. Quem está ficando para trás? Uma década de evasão nos cursos brasileiros de graduação em Administração de Empresas e Ciências Contábeis. Revista de Educação e Pesquisa em Contabilidade - REPeC, v. 9, n. 2, p. 124-142, 2015.

CUNHA, J. V. A.; NASCIMENTO, E. M.; DURSO, S. O. Razões e influências para a evasão universitária: um estudo com estudantes ingressantes nos cursos de Ciências Contábeis de instituições públicas federais da região sudeste. Advances in Scientific and Applied Accounting, v. 9, n.2, p. 141-161, 2016.

DIAS, E. C. M.; THEÓPHILO, C. R.; LOPES, M. A. S. Evasão no ensino superior: estudo dos fatores causadores da evasão no curso de Ciências Contábeis da Universidade de Montes Claros - UNIMONTES - MG. In: CONGRESSO USP DE INICIAÇÃO CIENTÍFICA EM CONTABILIDADE, 7., 2010, São Paulo. Anais... São Paulo: USP, 2010. Disponível em: $<$ http://www.congressousp.fipecafi.org/anais/artigos102010/419.pdf >. Acesso em: 01 jan. 2017.

DIOGO, M. F.; RAYMUNDO, L. dos S.; WILHELM, F. A.; ANDRADE, S. P. C. de; LORENZO, F. M.; ROST, F. T.; BARDAGI, M. P. Percepções de coordenadores de curso superior sobre evasão, reprovações e estratégias preventivas. Avaliação: Revista da Avaliação da Educação Superior, v. 21, n. 1, p. 125-151, Mar. 2015.

DRAPER, N. R.; SMITH, H. A. Applied regression analysis. 3, ed. New York: John Wiley, 1998.

KRÜGER JÚNIOR, P. R.; MELLO, S. P. T. D.; DINIZ, R. M.; SANTOS, E. G. D.; NEUENFELDT, C. S.; BARBOSA, L. P. Pesquisando causas e possíveis soluções para a problemática da evasão em um curso de administração numa universidade pública no sul do Brasil. In: Colóquio Internacional sobre Gestão Universitária na América do Sul, 9., e 
Congresso Internacional IGLU, 2., 2011, Florianópolis (SC). Anais... Florianópolis: UFSC, 2011.

LOBO, M. B. de C. M. Panorama da evasão no ensino superior brasileiro: aspectos gerais das causas e soluções. Associação Brasileira de Mantenedoras do Ensino Superior- ABMES Cadernos, n. 25, p. 09-58, 2012. Disponível em:

<http://www.abmes.org.br/abmes/public/arquivos/publicacoes/Cadernos25.pdf>. Acesso em: 20 jan. 2016.

MIRANDA, G. J.; LEMOS, K. C. S.; PIMENTA, A. S. de O.; FERREIRA, M. A. Determinantes do Desempenho Acadêmico na Área de Negócios. Revista Meta: Avaliação, n. 7, v. 20, p. 175-209, 2013.

MUNIZAGA, F., CIFUENTES, M., \& BELTRÁN, A. Retención y abandono estudiantil en la Educación Superior Universitaria en América Latina y el Caribe: Una revisión sistemática. Archivos Analíticos de Políticas Educativas, v. 26, n. 61, p. 61, 2018. Disponível em: <http://dx.doi.org/10.14507/epaa.26.3348>. Acesso em: 20 out. 2018.

PAES BARROS, R.; FRANCO, S.; GALL, G.; GARCIA, B.; MENDONÇA, R. Políticas públicas para redução do abandono e evasão escolar de jovens. 2016. Disponível em: < https://www.insper.edu.br/wp-content/uploads/2018/09/Poli\%CC\%81ticaspu\%CC\%81blicas-para-a-reduc\%CC\%A7a\%CC\%83o-do-abandono-e-evasa\%CC\%83oescolar-de-jovens.pdf>. Acesso em: 12 dez. 2019.

R DEVELOPMENT CORE TEAM. R: A language and environment for statistical computing. R Foundation for Statistical Computing, Vienna, Austria. Disponível em: <http://www.R-project.org/>. Acesso em: 10 dez. 2016.

SEMESP-SINDICATO DAS MANTEDORAS DE ENSINO SUPERIOR. Mapa do Ensino Superior no Brasil 2015. Disponível em:<http://convergenciacom.net/pdf/mapa-ensinosuperior-brasil-2015.pdf>. Acesso em: $01 \mathrm{dez} 2016$.

SILVA FILHO, R. L. L.; MOTEJUNAS, P. R.; HIPÓLITO, O.; LOBO, M. B. de C. M. A evasão no ensino superior brasileiro. Cadernos de Pesquisa, n. 37, v. 132, p. 641-659, 2007. Disponível em: <http://www.institutolobo.org.br/imagens/pdf/artigos/art_045.pdf>. Acesso em: 20 jan. 2016.

SILVA, G. P. Análise de evasão no ensino superior: uma proposta de diagnóstico de seus determinantes. Revista de Avaliação da Educação Superior, n. 18, n. 2, p. 311-333, 2013.

TINTO, V. Dropout from higher education: a theoretical synthesis of recent research. Review of Educational Research, v. 45, n. 1, p. 89-125, 1975.

TINTO, V. Leaving College: Rethinking the Causes and Cures of Student Attrition. Chicago: University of Chicago Press, 1993. 